\title{
Numerical Investigation of Different Tip Clearances Effect on the Hydrodynamic Performance of Pumpjet Propulsor
}

\author{
Denghui Qin*, Guang Pan ${ }^{\dagger}$, Qiaogao Huang, \\ Zhengdong Zhang and Jiujiu Ke \\ School of Marine Science and Technology \\ Northwestern Polytechnical University \\ Xi'an 710072, P. R. China \\ Key Laboratory for Unmanned Underwater Vehicle \\ Northwestern Polytechnical University \\ $X i$ 'an 710072, P. R. China \\ *18729869394@163.com \\ †panguang@nwpu.edu.cn
}

Received 9 September 2016

Revised 17 August 2017

Accepted 25 August 2017

Published 16 November 2017

\begin{abstract}
Previous studies show that the tip clearance loss limits the improvement of turbomachinery performance, and it is roughly in close relation with the gap size. In this study, a pumpjet propulsor (PJP) with different sizes of tip clearances $(\delta=0.2,0.5,1,2,3 \mathrm{~mm})$ has been presented to investigate the influence of tip clearances on PJP. This analysis is based on computational fluid dynamic (CFD) method, and the SST k- $\omega$ turbulence model is applied. Calculations are carried out with a worldwide employed ducted propeller (the Ka4-70 propeller in 19A duct) to verify the numerical simulation. And the grid independence validation is discussed. The numerical simulation of PJP flow with different tip clearances is carried out. Results show that the open water efficiency decreases gradually with the increase of tip clearance. The efficiency decreasing is caused by the tip flow loss. The shape of tip vortex of PJP which consisted of tip-separation vortex and tip-leakage vortex is presented. Furthermore, the formation and spread process of tip vortex at different tip clearances are discussed. Then, the effect of different tip clearances on the pressure field of rotor blade is investigated. The main pressure area affected by different tip clearances is mainly concentrated in the area above 0.9 spanwise of the suction side of rotor blade. Beyond that, the effects of different tip clearances on the velocity field of PJP has been studied.
\end{abstract}

Keywords: Pumpjet propulsor; tip clearance; the tip vortex; the hydrodynamic performance.

${ }^{\dagger}$ Corresponding author.

This is an Open Access article published by World Scientific Publishing Company. It is distributed under the terms of the Creative Commons Attribution 4.0 (CC-BY) License. Further distribution of this work is permitted, provided the original work is properly cited. 


\section{Introduction}

Pumpjet propulsor is a new type of underwater propulsion system, which adopts single-rotor propulsion and decelerating duct. The application of decelerating duct improves the cavitation performance of the propulsion system at a lower velocity. At present, the research on the characteristics of pumpjet propulsor, domestic and international published literatures mainly concentrate on the test and numerical calculation of hydrodynamic performance. Ch. Suryanarayana et al. [2010] make experiment on hydrodynamic performance of the underwater vehicle equipped with pumpjet propulsor. They verify the advantages of the rear stator pumpjet propulsor and indicate that the rear stator can absorb the rotational energy of the rotor, reduce the radial component in the wake, and improve the efficiency of the propulsion. Ivanell [2001] uses computational fluid dynamics method (CFD) to calculate the hydrodynamic performance of the torpedo with pump jet, and the rationality of the method is verified by comparing with the experimental results. The numerical results show that the stator has contributed about $20 \%$ of the thrust. The numerical results and the experimental results are in good agreement. Pan et al. 2013] carry numerical calculation to the vehicle equipped with a certain type of water pump jet propulsion. The open water performance curve of pump jet propeller is given and it indicates that the pumpjet propulsor has higher efficiency and ideal balance performance. Pressure distributions along with the meridian of vehicle hull and at various heights of blade were analyzed. Lu et al. [2016] investigate the influence of rotational speed and tip clearance size on tip clearance cavitation. By analyzing the local flow field, the influence of the clearance flow on the flow fields (including velocity and pressure fields) is revealed. In addition, most of the studies about the flow of tip clearance are aimed at the duct propeller or axial flow pump. For example,

Lee et al. [2003] study the flow of tip clearance of the ducted propeller by solving three-dimensional RANS equations. The calculated results are in good agreement with experimental results. It is shown that the numerical method is feasible for the study of tip clearance flow. Peng et al. [2013] study the steady-state tip vortex flow of a David Taylor Model Basin (DTMB) propeller model using a RANS solver on a spiral-like structured grid with grid concentration aligned with the vortex core. Ji et al. [2010] investigate the unsteady cavitating turbulent flow around a full scale marine propeller operated in non-uniform ship wake. Quantitative studies on tip clearance of turbomachinery have been presented Xiao et al. (2001); Mccarter et al. (2001); Booth (1985); Yaras and Siolander (1992); Yaras et al. (1992)]. Although ducted propeller and turbomachinery are different with pumpjet propulsor, the results of duct propeller and axial flow pump researches have a good reference to the research of tip clearance flow of pumpjet propulsor.

In this paper, a pumpjet propulsor (PJP) with different sizes of tip clearances $(\delta=0.2,0.5,1,2,3 \mathrm{~mm})$ has been presented. The high quality structured grid is generated based on the block grid coupling technique. And the grid independence inspection is discussed to verify accuracy of numerical simulation grid. By means of 
numerical simulation, based on the sliding grid technique, the numerical simulation of three-dimensional full channel steady turbulent flow is carried out. Calculations are carried out with a worldwide employed ducted propeller (the Ka4-70 propeller in $19 \mathrm{~A}$ duct) to verify the numerical simulation. Then, the numerical simulation of PJP flow with different tip clearances is carried out. The tip clearance loss is generated by the leakage flow through the tip clearance. The shape of tip vortex of PJP is presented to research the detail of the tip leakage flow. Furthermore, the formation and spread process of tip vortex at different tip clearances are discussed. Finally, the effect of different tip clearances on the pressure and velocity field of rotor blade is investigated. All in all, the effect of different tip clearances on the hydrodynamic performance of Pumpjet Propulsor is researched. And the research conclusion will be important to improve the efficiency of Pumpjet Propulsor and help the design of it.

\section{Numerical Simulation Method}

\subsection{Governing equations}

The governing equations of incompressible and single phase fluid flow which is Reynolds Averaged Navier-Stokes (RANS) equations that can be written as the mass and momentum conservations in the following tensor form:

$$
\begin{aligned}
& \frac{\partial \rho U_{j}}{\partial x_{j}}=0, \\
& \frac{\partial\left(\rho U_{i} U_{j}\right)}{\partial x_{j}}=\frac{\partial}{\partial x_{j}}\left(\mu \frac{\partial U_{i}}{\partial x_{j}}\right)+\frac{\partial \tau_{i j}}{\partial x_{j}}-\frac{\partial P}{\partial x_{i}}+S_{M},
\end{aligned}
$$

where $\rho$ is the fluid density, $x_{i}$ and $x_{j}(i=1,2,3, j=1,2,3)$ are the Cartesian coordinate components, respectively. $S_{M}, U_{i}$ and $U_{j}$ are different values depending on different situations. For an inertial frame, $S_{M}$ equals zero, $U_{i}$ and $U_{j}$ represents the absolute velocity component. For a relative rotating frame, $S_{M}$ is the sum of Coriolis $(2 \boldsymbol{\omega} \times \mathbf{U})$ and centrifugal forces $(\boldsymbol{\omega} \times(\boldsymbol{\omega} \times \mathbf{r})), U_{i}$ and $U_{j}$ represent the relative velocity components. $\mu$ is the dynamic viscosity, $t$ is the time, $\tau_{i j}$ denotes the Reynolds stresses. $P$ and $\mathbf{U}$ represent the pressure and the time averaged velocity, respectively.

\subsection{Turbulence model}

Currently, the most prominent two-equation models of the turbulence model are the $k-\omega$-based models of Menter 1994. The $k-\omega$-based Shear-Stress-Transport (SST) model was designed to give a highly accurate prediction of the onset and the amount of flow separation under adverse pressure gradients by the inclusion of transport effects into the formulation of the eddy-viscosity. This results in a 
major improvement in terms of flow separation predictions. The superior performance of this model has been demonstrated in a large number of validation studies (Bardina et al. [1997]). The SST $k-\omega$ turbulence model is applied for the numerical simulation of propeller according to the existing study by Ji et al. [2010]. The SST $k-\omega$ turbulence model can utilize the inner viscous layer combined with the wall function to accurately simulate the phenomenon of the boundary layer without the use of easier distortion viscous-attenuation function.

For a very fine near-wall mesh to examine details of the boundary layer, the SST model with Automatic Near-Wall Treatment should be used to take advantage of the additional effect in the viscous sublayer [Documentation A. N. S. Y. S. (2002)]. Automatic Near-Wall Treatment automatically switches from wall-functions to a low-Re near wall formulation as the mesh is refined. However, a strict low-Reynolds number implementation of the $k-\omega$ model would also require a near wall grid resolution of at least $y^{+}<2$. This condition cannot be guaranteed in most applications at all walls. For this reason, a new near wall treatment was developed by CFX for the $k-\omega$-based models that allows for a smooth shift from a low-Reynolds number form to a wall function formulation. This near wall boundary condition, named Automatic Near Wall Treatment in CFX, is used as the default in the SST model.

\subsection{Verification}

In this paper, numerical verification is carried out with a worldwide employed ducted propeller (the Ka4-70 propeller in 19A duct), which was presented by Maritime Research Institute Netherland (MARIN) (Oosterveld et al. [1970]). The geometry data of the ducted propeller is presented in Table 1 The computational domain and

Table 1. Parameters of the Ka4-70 propeller in 19A duct.

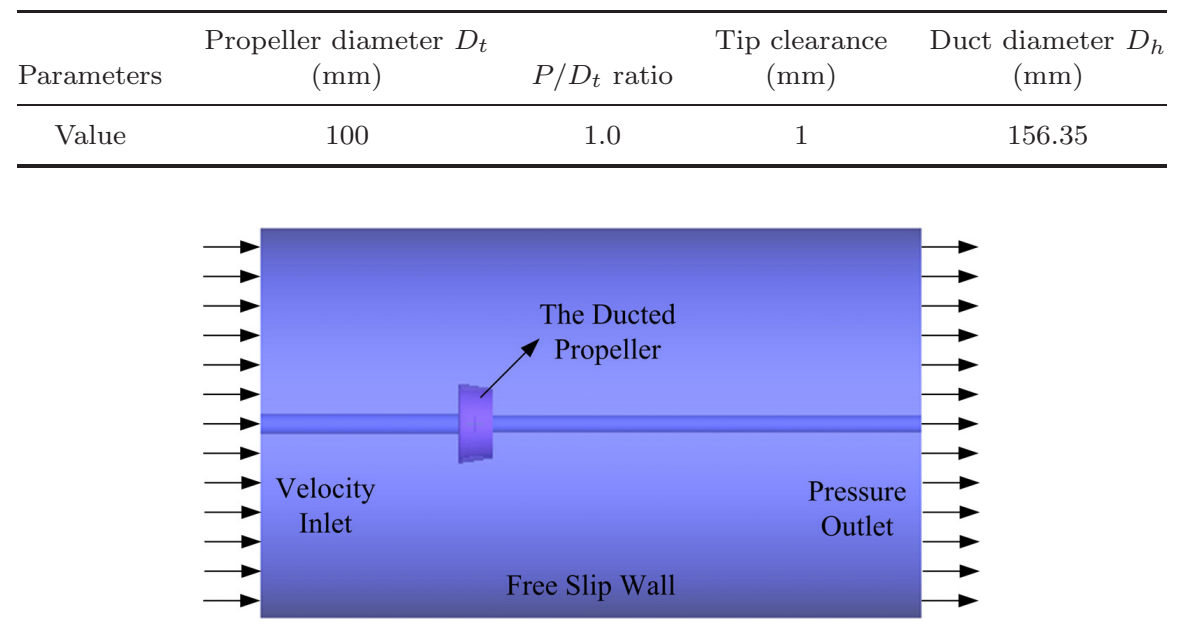

Fig. 1. Computational domain and boundary conditions for E779A propeller. 
boundary conditions for E779A marine propeller are a cylinder passage as shown in Fig. 1

The advance ratio $J$ is defined as $J=U_{\infty} /\left(n D_{h}\right)$, where $U_{\infty}$ denotes the free stream velocity, $n$ is the blade rotating velocity. The thrust coefficient $K_{T}=$ Thrust $/\left(\rho_{f} n^{2} D_{h}^{4}\right)$ and torque coefficient $K_{Q}=$ Torque $/\left(\rho_{f} n^{2} D_{h}^{5}\right)$ are defined, respectively. The relative percentage errors $\Delta K_{T}$ and $\Delta K_{Q}$ were defined as Morgut and Nobile (2012)]

$$
\begin{aligned}
& \Delta K_{T}(\%)=\frac{\Delta K_{T C F D}-\Delta K_{T E X P}}{\Delta K_{T E X P}} * 100, \\
& \Delta K_{Q}(\%)=\frac{\Delta K_{Q C F D}-\Delta K_{Q E X P}}{\Delta K_{Q E X P}} * 100 .
\end{aligned}
$$

According to the existing study by Peng et al. [2013], eddy viscosity turbulence models are slightly better than Reynolds stress models in the prediction of tip vortex flow and the thrust and torque coefficients. In order to investigate the effect of turbulence models on the simulation, Standard $k-\varepsilon$; Realizable $k-\varepsilon$ and SST $k-\omega$ turbulence models are calculated. The results of simulations which are represented by the relative errors of the thrust coefficient $\Delta K_{T}$ and the torque coefficient $\Delta K_{Q}$ at different advance ratios are shown in Table 2

As is presented in Table 2 we can see that the maximum relative error of the thrust coefficient and the torque coefficient of SST $k-\omega$ turbulence model is $2.5 \%$ at $J=0.7$, while the errors of Standard $k-\varepsilon$ and Realizable $k-\varepsilon$ turbulence model are a little bigger than SST $k-\omega$ turbulence model. So SST $k-\omega$ turbulence model is chosen for the numerical simulation and the computed results have a good agreement with the experimental data. Consequently, it is indicated that the numerical simulation method with the $S S T k-\omega$ turbulence model and Automatic Near-Wall Treatment is applicable and reliable for the numerical simulation of pumpjet propulsor flows.

Table 2. The results of different turbulence models.

\begin{tabular}{lccc}
\hline & & \multicolumn{2}{c}{ Relative errors (\%) } \\
\cline { 3 - 4 } Turbulence Model & $J$ & $\Delta K_{T}$ & $\Delta K_{Q}$ \\
\hline Standard $k-\varepsilon$ & 0.5 & 3.5 & 2.3 \\
& 0.6 & 3.2 & 3.1 \\
Realizable $k-\varepsilon$ & 0.7 & 2.6 & 2 \\
SST $k-\omega$ & 0.5 & 3.2 & 2.3 \\
& 0.6 & 2.2 & 3.1 \\
& 0.7 & 2.6 & 3.9 \\
& 0.5 & 2.3 & 1.9 \\
& 0.6 & 1 & 2 \\
& 0.7 & 2.5 & 2.2 \\
\hline
\end{tabular}


D. Qin et al.

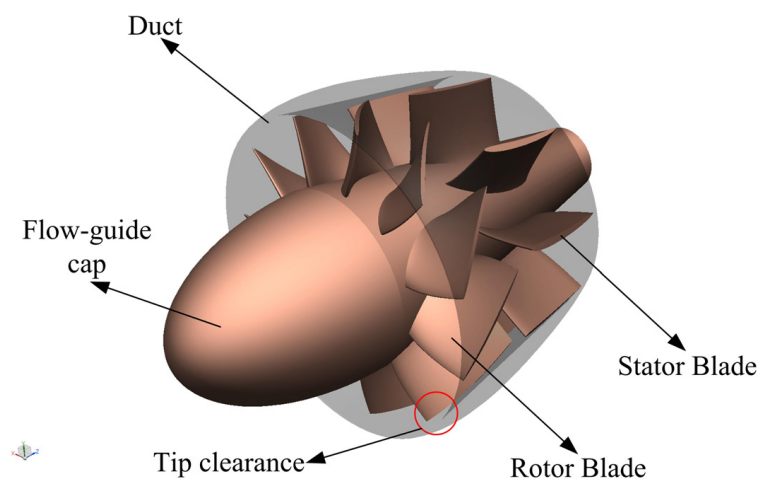

Fig. 2. The pumpjet propulsor model.

\section{Numerical Simulation of Pumpjet Propulsor}

\subsection{Model geometry}

The pumpjet propulsor geometry model in this study is shown in Fig. 2, the propeller has 11 rotor blades, 9 stator blades. The rotors are in front of the stators, and the rotors rotate clockwise (seen from the front of the model). The diameter of pumpjet propulsor is $D=0.26 \mathrm{~m}$ and the length of pumpjet propulsor is $L=0.17 \mathrm{~m}$.

In order to get more precise results, two half ellipsoid type flow-guide caps have been added in the front and rear of the propulsor model. In order to study the effect of different tip clearances on the performance of pumpjet propulsor, different diameters of the duct have been selected to get models with different tip clearances. Five models with $0.2,0.5,1,2$ and $3 \mathrm{~mm}$ tip clearances have been generated. In order to facilitate the discussion, $\delta$ has been defined to represent the tip clearance.

\subsection{Computational domain and mesh}

The computational domain and boundary conditions are shown in Fig. 3. The computational domain is a cylinder whose length and diameter are $10 L$ and $5 D$, respectively, and the axis coincides with the symmetry axis of propulsor model. The inlet is located $3 L$ from the front face of the model, and the outlet is situated $7 \mathrm{~L}$ from the front face of the model. The computational domain is divided into three parts, rotor domain, stator domain and external flow field domain. The rotor domain is a rotating domain, and the other two domains are stationary domains. The interaction between the rotor domain and stator domain and the interaction between the rotor domain and external flow field domain are solved by using the sliding mesh method.

The quality of the computational grid directly affects the results of numerical simulations. The structured grid is very favorable for the boundary layer calculation. Therefore, the structured grids are used in this investigation and multi-blocks grid 


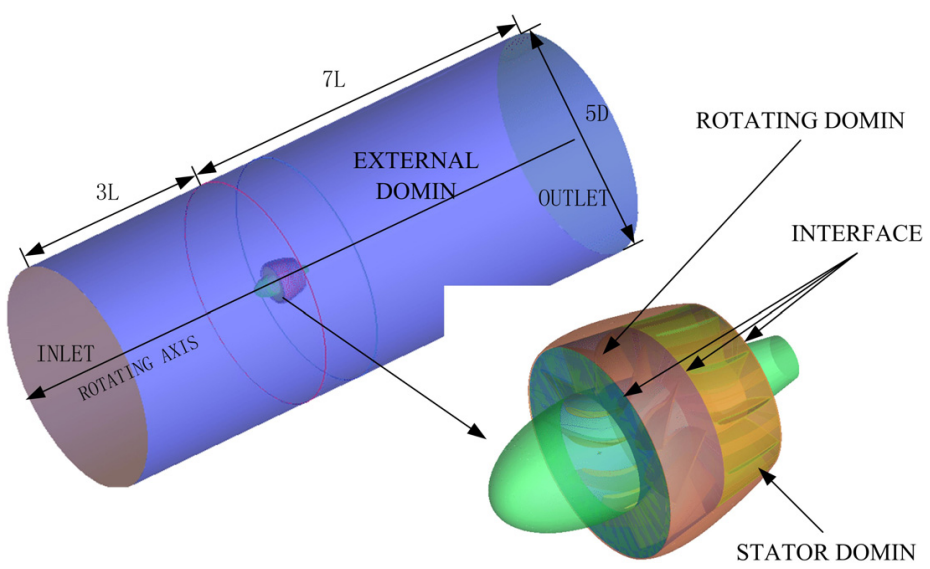

Fig. 3. The computational domain and boundary conditions.

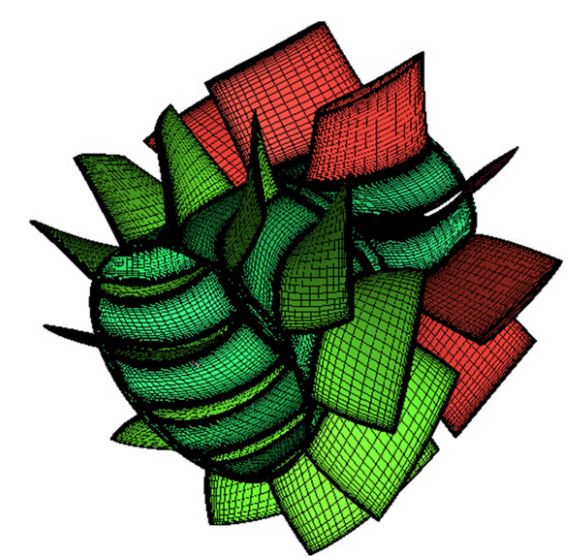

Fig. 4. The rotor and stator blades surface grids.

method is used to generate high-quality structured grid by ANSYS ICEM (Version 14.5, ANSYS Inc.). The grids around PJP are H-grids and the PJP surface and propulsor blades are surrounded by O-hexahedral girds. Figure 4 shows the rotor and stator blades surface grids. In addition, in order to accurately capture the phenomenon of tip vortex, the tip clearance is refined and the first layer mesh height is $0.05 \mathrm{~mm}$. Figure [5 shows the mesh refinement between the rotor blades and the duct in the case of $\delta=3 \mathrm{~mm}$. The number of entire computational domain grids is approximately $3 \times 10^{6}$.

\subsection{Boundary condition}

For computational domain boundary conditions, the inlet boundary is set as normal speed and the turbulence intensity is $5 \%$ as the default. The no-slip boundary 
D. Qin et al.

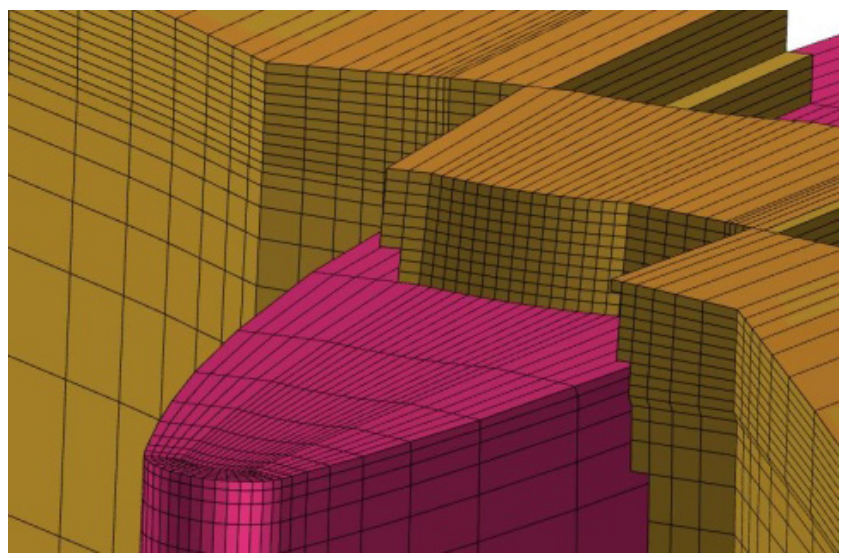

Fig. 5. The mesh refinement of tip clearance in the case of $\delta=3 \mathrm{~mm}$.

condition is imposed on duct and stator blades. The free-slip wall boundary is applied on the cylinder surface. The averaged static pressure is set as $10 \mathrm{MPa}$ at the outlet. The interface between the rotor domain and stator domain is set as frozen rotor. The spatial derivatives are calculated using a second-order upwind algorithm. The flow of PJP is solved by ANSYS CFX (Version 14.5, ANSYS Inc.) based on finite volume method solver.

\section{Results and Discussion}

To facilitate the discussion of calculation results, the nondimensional physical quantities are shown in Table 3

In the table, $v$ is the far field flow velocity; $n$ is rotor speed $(r / s) ; D$ is the diameter of the rotor; $\rho$ is the fluid density; $T_{t}$ is the thrust of rotor; $T_{s}$ is the thrust

Table 3. Nondimensional physical quantities.

\begin{tabular}{ll}
\hline Physical quantities & Definition \\
\hline Advance coefficient & $J=\frac{v}{n * D}$ \\
The thrust coefficient of rotor & $K_{T_{t}}=\frac{T_{t}}{\rho n^{2} D^{4}}$ \\
The torque coefficient of rotor & $K_{M_{t}}=\frac{M_{t}}{\rho n^{2} D^{5}}$ \\
The thrust coefficient of stator and duct & $K_{T_{s}}=\frac{T_{S}}{\rho n^{2} D^{4}}$ \\
The torque coefficient of stator and duct & $K_{M_{s}}=\frac{M_{s}}{\rho n^{2} D^{5}}$ \\
Total thrust coefficient & $K_{T}=K_{T_{t}}+K_{T_{s}}$ \\
Total torque coefficient & $K_{M}=K_{M_{s}}$ \\
The open water efficiency & $\eta=\frac{J}{2 \pi} \frac{K_{T}}{K_{M}} \delta$ \\
\hline
\end{tabular}


of stator and duct; $M_{t}$ is the torque of rotor and $M_{t}$ and $M_{s}$ are the torque of stator and duct.

\subsection{Grid independence validation}

In this section, mesh independence validation is conducted. Mesh independence is tested by assessing the open water efficiency of the PJP for different mesh densities. Three different scale grids are generated to validate the mesh independence $(1.5 \times$ $10^{6}, 3 \times 10^{6}$ and $6 \times 10^{6}$ elements) according to the first grid heights of $0.1,0.05$, and $0.025 \mathrm{~mm}$, respectively. The open water efficiency numerical results of the three different grids with different advance coefficient in the case $\delta=3 \mathrm{~mm}$ are shown in Table 4 .

In Table 4 it indicates that the results of $3 \times 10^{6}$ and $6 \times 10^{6}$ elements grids are about the same comparing to that of $1.5 \times 10^{6}$ elements grids. Accordingly, the mesh with approximately $3 \times 10^{6}$ elements is sufficient for the mesh independence study. And this mesh density is propitious to ensure the higher computation efficiency.

\subsection{Effects of different tip clearances on the open water performance of PJP}

In the case of $\delta=3 \mathrm{~mm}$, the velocity of inlet is $25.72 \mathrm{~m} \cdot \mathrm{s}^{-1}$ and the open water performance is studied with different rotational speeds under different rotational speeds $(n)$ that vary from $2400 \mathrm{rpm}$ to $4200 \mathrm{rpm}$. Figure 6 shows the thrust and torque coefficient and open water efficiency curves.

It can be seen from Fig. [6 that the thrust coefficient of rotor $K_{T_{t}}$ is obviously bigger than the thrust coefficient of stator and duct system $K_{T_{s}}$, so the rotor provides the main thrust of PJP. Also the thrust and torque coefficient are gradually reduced with the increase of the advance coefficient $J$. Besides, the thrust coefficient of the stator and duct system varies almost linearly with the increase of the advance coefficient $J$. What's more, the thrust coefficient of the stator and duct

Table 4. The open water efficiency numerical results of the three grids with different advance coefficient in the case $\delta=3 \mathrm{~mm}$.

\begin{tabular}{rrrrcc}
\hline $\mathrm{J}$ & \multicolumn{1}{c}{ Grids } & $K_{T_{t}}$ & \multicolumn{1}{c}{$K_{T_{s}}$} & $K_{M_{t}}$ & $K_{M_{s}}$ \\
\hline 2.54 & $1.5 \times 10^{6}$ & 0.5548 & -0.1487 & 0.2799 & 0.2639 \\
& $3 \times 10^{6}$ & 0.5536 & -0.1474 & 0.2790 & 0.2626 \\
& $6 \times 10^{6}$ & 0.5533 & -0.1470 & 0.2794 & 0.2628 \\
1.79 & $1.5 \times 10^{6}$ & 0.6785 & 0.0469 & 0.3027 & 0.2917 \\
& $3 \times 10^{6}$ & 0.6775 & 0.0457 & 0.3016 & 0.2902 \\
& $6 \times 10^{6}$ & 0.6778 & 0.0455 & 0.3014 & 0.2904 \\
1.52 & $1.5 \times 10^{6}$ & 0.7055 & 0.1161 & 0.2994 & 0.2867 \\
& $3 \times 10^{6}$ & 0.7045 & 0.1171 & 0.2986 & 0.2888 \\
& $6 \times 10^{6}$ & 0.7043 & 0.1173 & 0.2984 & 0.2885 \\
\hline
\end{tabular}


D. Qin et al.

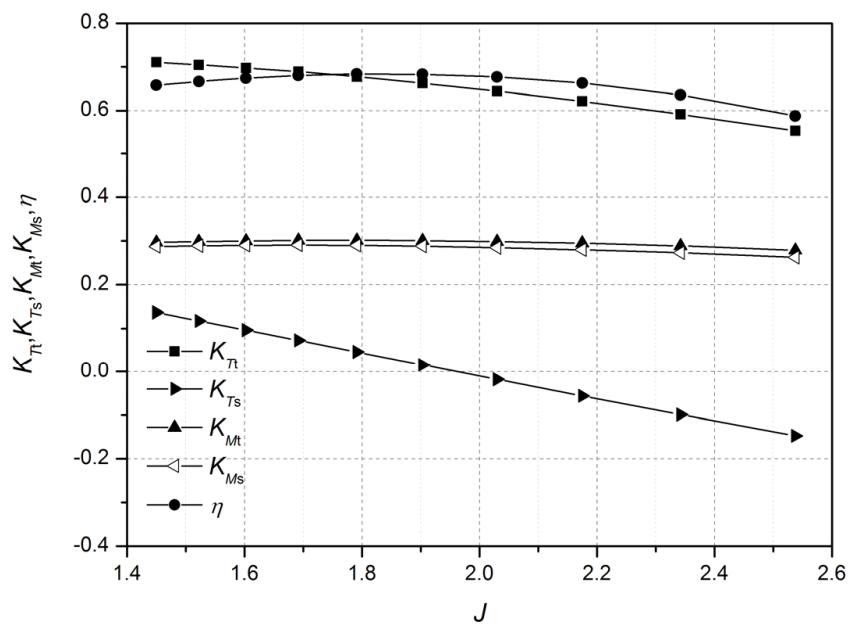

Fig. 6. Thrust and torque coefficient and open water efficiency curves.

system changes from trust to resistance with the increase of $J$. And the open water efficiency firstly increases, then decreases with the increase of $J$, especially reaching peak value about $71.5 \%$ at $J=1.9$ in the case of $\delta=0.2 \mathrm{~mm}$.

In order to explore the effects of different tip clearances on the open water performance of PJP, different models with $0.2,0.5,1,2$ and $3 \mathrm{~mm}$ tip clearance are calculated. Figure 7 shows the open water efficiency results of the five models.

As shown in Fig. 7 the open water efficiency curves of different tip clearance models are presented. The five open water efficiency curves of different tip clearance models change in the same trend, which first increase and then decrease with the

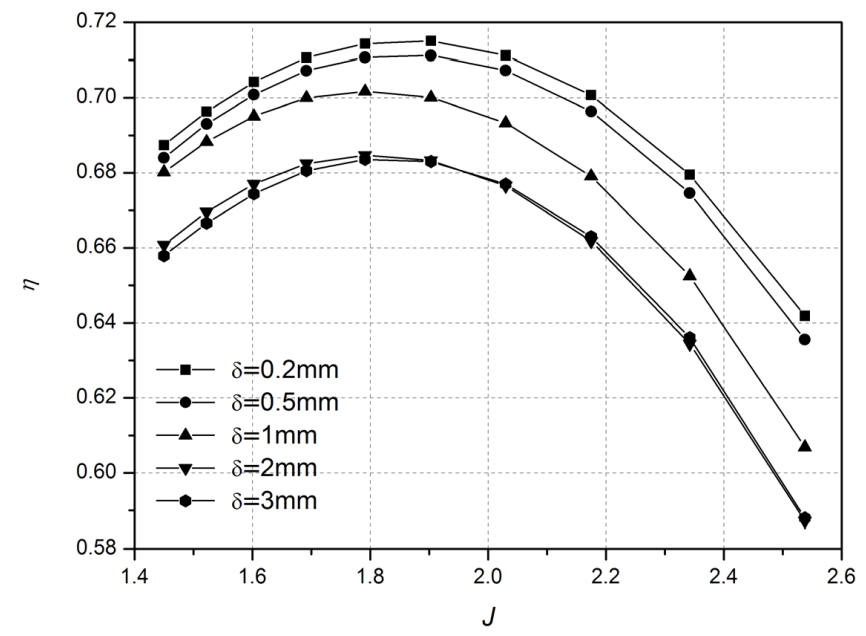

Fig. 7. The open water efficiency results of different tip clearance models. 
increasing of the advance ratio $J$, but the peaks present at different advance ratio. The open water efficiency of PJP reaches its maximum at $J \approx 1.9$ in the case $\delta=0.2$ and $\delta=0.5 \mathrm{~mm}$, but at $J \approx 1.8$ in the case $\delta=1, \delta=2$ and $\delta=3 \mathrm{~mm}$.

Comparing the five curves, it indicates that the open water efficiency decreases gradually with the increase of tip clearance in the same advance ratio $J$. For $\delta=$ $0.2 \mathrm{~mm}$, the open water efficiency of PJP is $71.5 \%$ at $J=1.9$ in contrast with $68.30 \%$ in the case $\delta=3 \mathrm{~mm}$. So, the tip clearance obviously affects the open-water efficiency of PJP, and the efficiency of PJP can be improved about $3 \%$ by reducing the tip clearance. Meanwhile, the open water efficiency of $\delta=2 \mathrm{~mm}$ is nearly the same as $\delta=3 \mathrm{~mm}$, so it indicates that there is little relation between the variation of the open water efficiency and the increasing of the tip clearance after clearance greater than $2 \mathrm{~mm}$ (about $8 \% \mathrm{D}$ ). Consequently, the tip clearance should be small to improve the open water efficiency of PJP.

\subsection{Effects of different tip clearances on the tip vortex structure of PJP}

Figure 8 shows the overview pressure contours of PJP in the case $\delta=3 \mathrm{~mm}$, and Fig. 9 shows the flow streamlines and local pressure contours of one rotor blade passage in the case $\delta=3 \mathrm{~mm}$. As shown in Fig. 8, the pressure distribution of different rotor blades is basically the same and so is to stator blades, which shows that the flow field of PJP achieves good convergence. From the pressure contour, it can be seen that the pressure of the rotor blade surface changes greatly, and the low pressure zone appears in the suction surface of the rotor blade near the leading edge and the tip of rotor blade. However, the pressure of the stator blade surface changes relatively smooth, and the low pressure region appears in the suction surface of the rotor blade near the leading edge too.

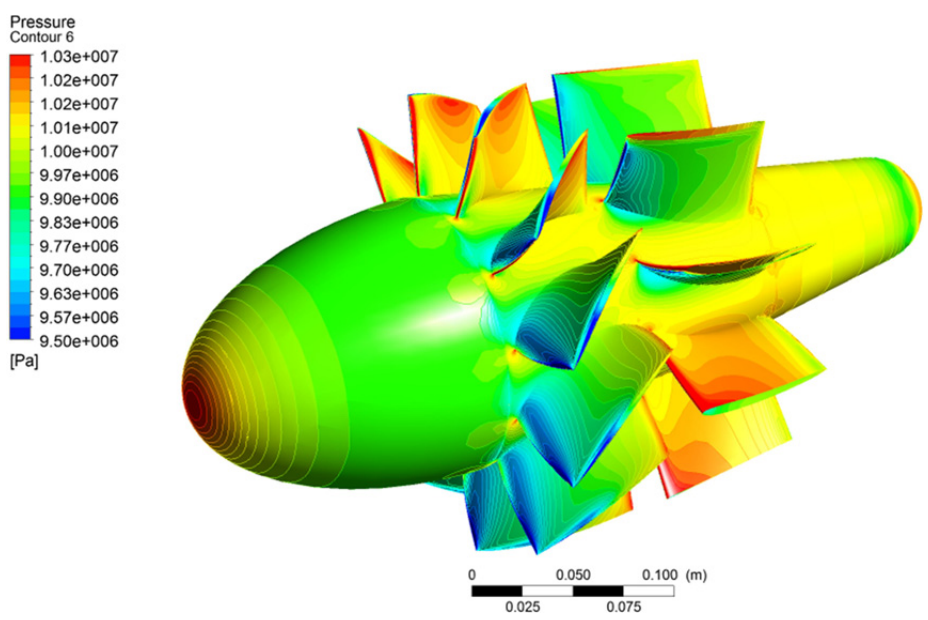

Fig. 8. The overview pressure contours of PJP in the case $\delta=3 \mathrm{~mm}$. 
D. Qin et al.

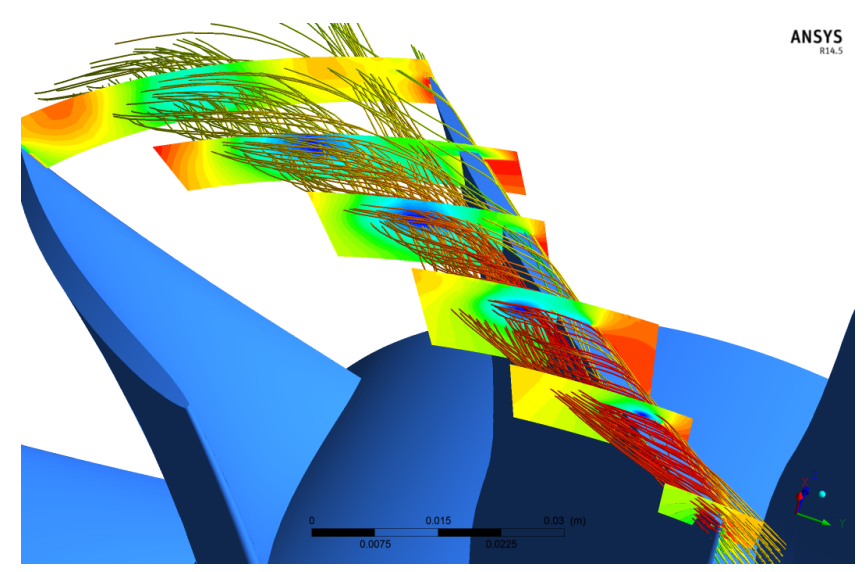

Fig. 9. The flow streamlines and local pressure contours of one rotor blade passage in the case $\delta=3 \mathrm{~mm}$.

It can be seen from Fig. 9 that the detail information of the flow field is well captured by the numerical simulation. In the tip of rotor blade, flow is sucked into the suction surface from the pressure side, and expands along the downstream direction. The large amount of rotation energy in the tip vortex flow cause severe flow loss of propeller. And the flow parameters in the tip vortex structure have strong unsteady fluctuation characteristics. In this paper, the effects of different tip clearances on the performance of the pump propeller are investigated. Therefore, the flow field near the rotor blade is emphatically analyzed as follows.

You et al. 2007] found that the tip vortex structure of ducted propeller is formed by three parts: the tip-separation vortex, the tip-leakage vortex and the induced vortex. The tip-leakage vortex is caused by the pressure difference between the pressure and the suction side. Besides the tip-separation vortex is formed due to flow separation underneath the blade tip and the induced vortex is generated by the tip-leakage vortex. Although the tip vortex structures of ducted propeller and PJP are different, the research conclusion of ducted propeller has important reference significance on the research of PJP. Because the strength and the influence area of induced vortex are small, the effect of different tip clearances on the tip-separation vortex and the tip-leakage vortex has been mainly analyzed in this paper.

Figure 10(a) shows the vortex core of rotor blade in the case $\delta=3 \mathrm{~mm}$ using the $\lambda_{2}$ vortex-identification [Jeong and Hussain [1995]). Figure[10(b) shows the flow streamlines near the rotor blade tip.

The pressure contours of pressure side and suction side of rotor blade in the case of $\delta=3 \mathrm{~mm}$ are illustrated in Figs. 11)(a) and 11](b). Figure 12] shows that the pressure contours near the tip of rotor blade in the case $\delta=3 \mathrm{~mm}$, and Fig. 13. shows that the turbulence kinetic energy of rotor blade in the case $\delta=3 \mathrm{~mm}$.

It can be seen from Figs. 10(a), 10(b), 12 that the rotor tip-separation vortex is caused by flow separation at the leading edge of the rotor blade tip. The rotor 


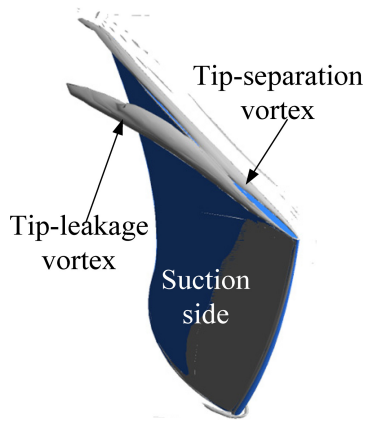

(a) The vortex core of rotor blade

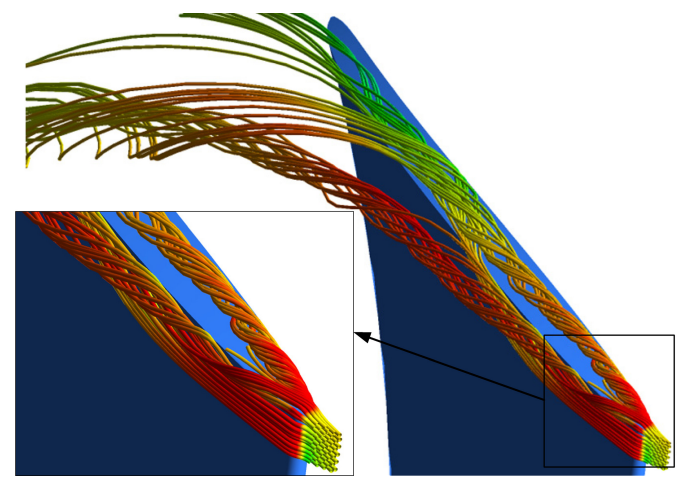

(b) The flow streamlines near the rotor blade tip

Fig. 10. In the case $\delta=3 \mathrm{~mm}$.

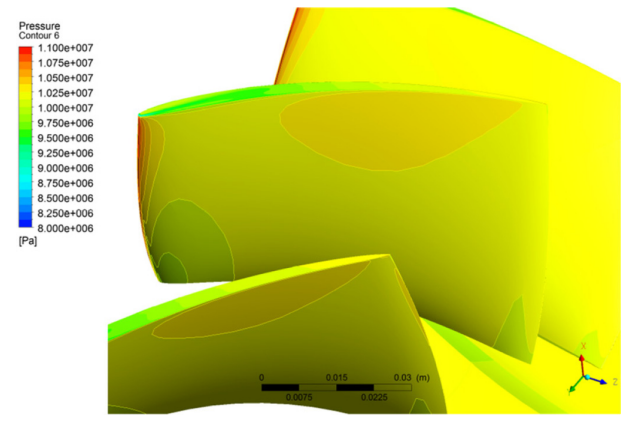

(a) The pressure side

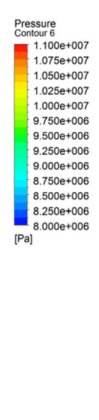

Fig. 11. The pressure contours of rotor blade in the case $\delta=3 \mathrm{~mm}$.

tip-separation vortex spreads in the axial direction along the rotor blade tip, leaving the trailing edge of rotor blade tip, and expanding to the stator passage finally. In the circumferential direction, the tip-separation vortex moves toward to the suction side of the rotor blade and cover the whole area of rotor blade.

As is shown in Fig. 10(a), the rotor tip-leakage vortex is formed at the top of the suction surface of the rotor blade near the leading edge. It can be seen from Figs. 11(b) and Fig. 12 that there is obvious low pressure area on the tip of the rotor blade near the leading edge. Simultaneously, obvious high pressure area is formed on the tip of pressure side of the rotor blade near the leading edge. The fluid flow is sucked to the low pressure area of the suction side due to the pressure difference, which causes the appearance of the rotor tip-leakage vortex. Figure 13 shows that the tip-separation vortex leaves the suction side of the rotor blade and moves toward to mid-passage with the spread of the vortex in the axial direction.

It can be seen through Fig. 10 (b) that the rotor tip-separation vortex and tipleakage vortex are not completely independent. A portion of the fluid separates from 
D. Qin et al.

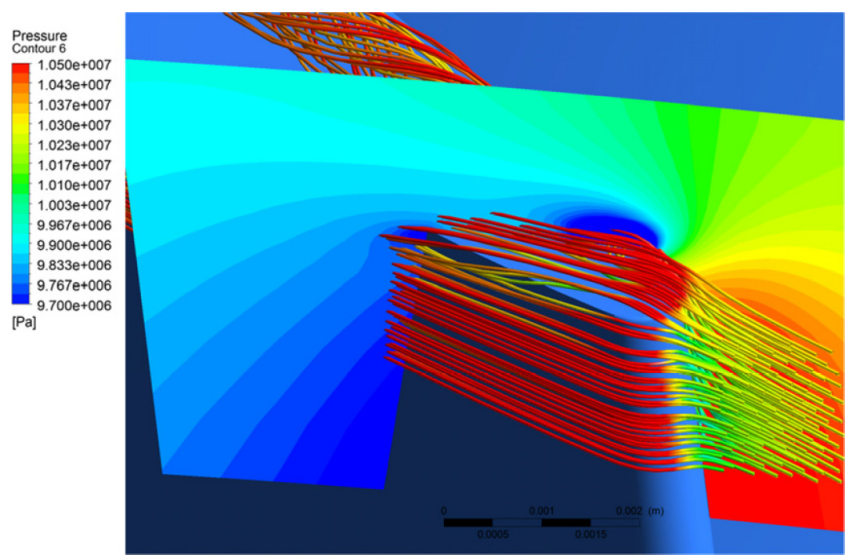

Fig. 12. The pressure contours near the tip of rotor blade in the case $\delta=3 \mathrm{~mm}$.

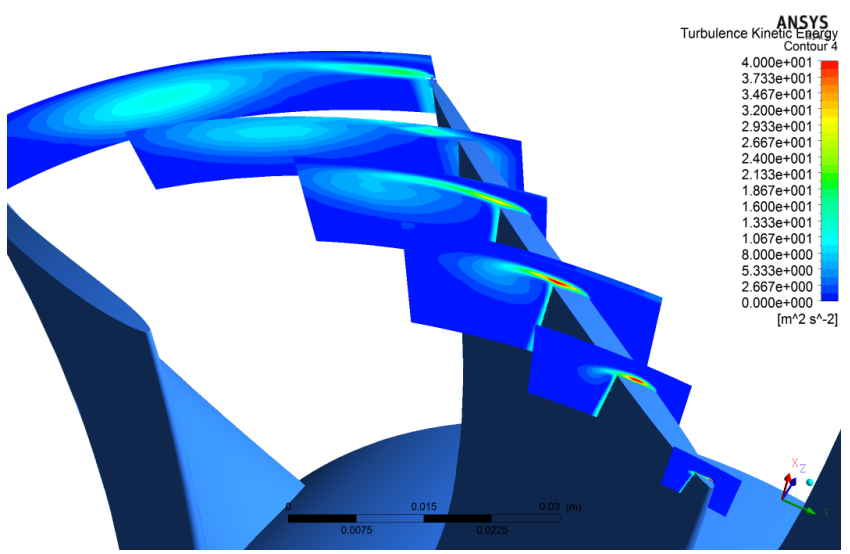

Fig. 13. The turbulence kinetic energy of rotor blade in the case $\delta=3 \mathrm{~mm}$.

tip-separation vortex and integrates into tip-leakage vortex. Meanwhile, a portion of the fluid separates from tip-leakage vortex and integrates into tip-separation vortex. So, the tip-separation vortex core and tip-leakage vortex core are connected and they transfer to each other.

In order to explore the effect of different tip clearances on the tip vortex structure of PJP, the vortex cores of rotor blade in the case of $\delta=0.2, \delta=1$ and $\delta=3 \mathrm{~mm}$ when $J=1.9$ are illustrated in Fig. 14. The flow streamlines near the rotor blade tip in the case $\delta=0.2 ; \delta=1$ and $\delta=3 \mathrm{~mm}$ when $J=1.9$ are illustrated in Fig. 15]

As is shown in Fig. 14 that the tip-separation vortex spreads toward the suction surface as the tip clearance increases, and the affected area is becoming larger and larger. The tip-separation vortex almost covers the whole area of the tip of rotor blade in the case of $\delta=3 \mathrm{~mm}$. As for tip-leakage vortex, it can be seen from 


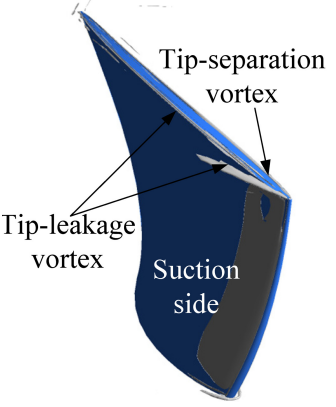

(a) $\delta=0.2 \mathrm{~mm}$

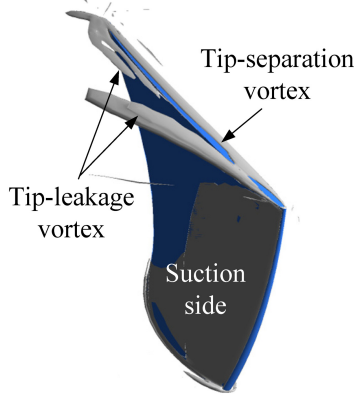

(b) $\delta=1 \mathrm{~mm}$

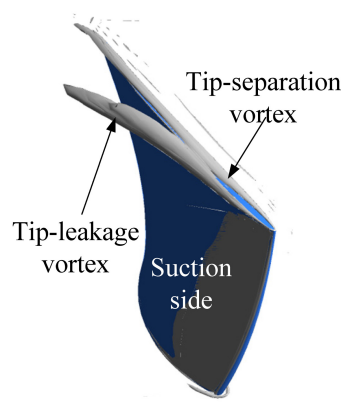

(c) $\delta=3 \mathrm{~mm}$

Fig. 14. The vortex core of rotor blade of different tip clearance.

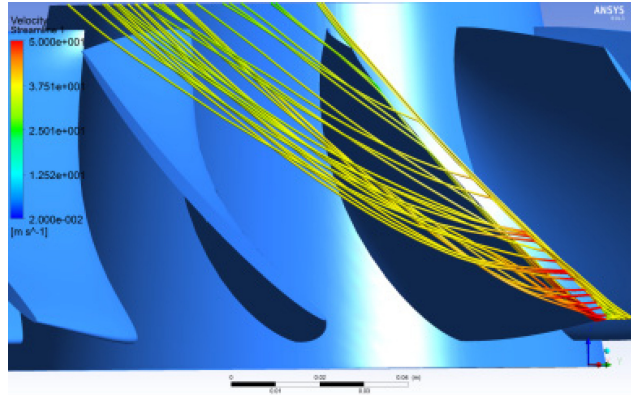

(a) $\delta=0.2 \mathrm{~mm}$

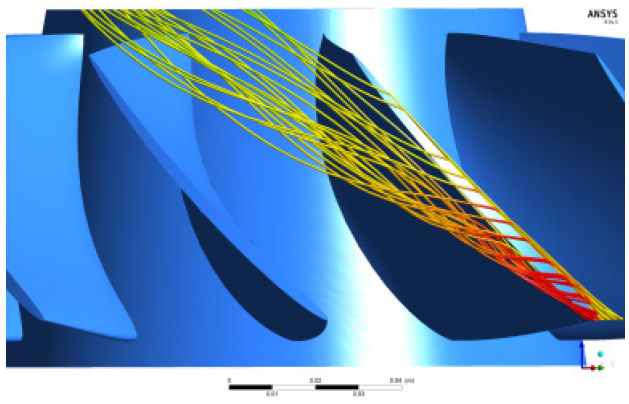

(b) $\delta=1 \mathrm{~mm}$

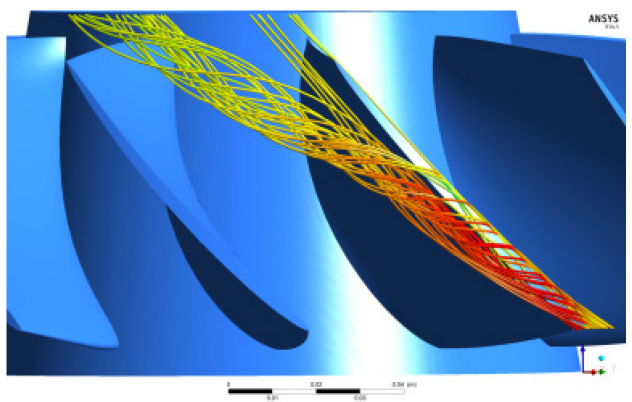

(c) $\delta=3 \mathrm{~mm}$

Fig. 15. The flow streamlines near the rotor blade tip of different tip clearance.

Fig. 15 that as the tip clearance increases, the affected area of tip-leakage vortex is becoming larger and larger too. The affected area is mainly focused on the area near the leading edge of the rotor blade in the case of $\delta=0.2 \mathrm{~mm}$, but the tip-leakage vortex almost affects the entire rotor passage in the case of $\delta=3 \mathrm{~mm}$. 


\section{Qin et al.}

Moreover, the distance between the tip-leakage vortex core and the suction side is larger with the increasing of the tip clearance, and the tip-leakage vortex core has moved to about $1 / 2$ in the middle of the passage in the case of $\delta=3 \mathrm{~mm}$. Finally the core of tip-separation vortex and tip-leakage vortex are connected, they transfer to each other. The connected position is moved to trailing edge in the axial direction with the increase of tip clearance, and the position is $1 / 3$ of the blade tip away from leading edge. So the tip-separation and tip-leakage vortexes are not independent and affect and contact mutually.

\subsection{Effects of different tip clearances on the pressure field of rotor blade}

Figures 16 and 17 show the pressure contours on the pressure side and suction side of the rotor blade with different tip clearance.

It can be seen from Fig. 17 that the main affected pressure area of different tip clearance mainly focus on the area above 0.9 spanwise of the suction side of rotor blade, but the effect of the pressure side is not obvious. For further understand of the effects on the pressure of suction side, the blade tip loading at constant span of 0.98 is illustrated in Fig. 18

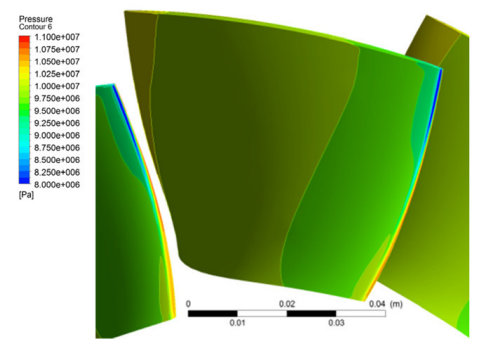

(a) $\delta=0.2 \mathrm{~mm}$

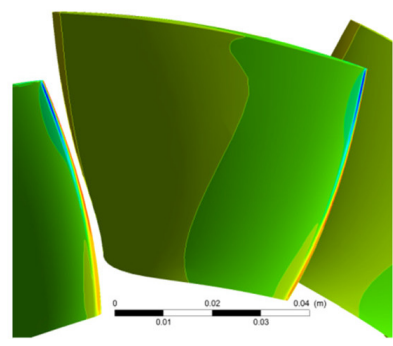

(b) $\delta=1 m m$

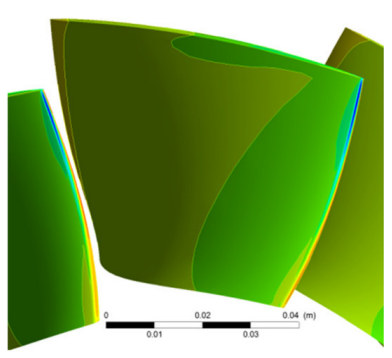

(c) $\delta=3 m m$

Fig. 16. The pressure contours of suction side of rotor blade.

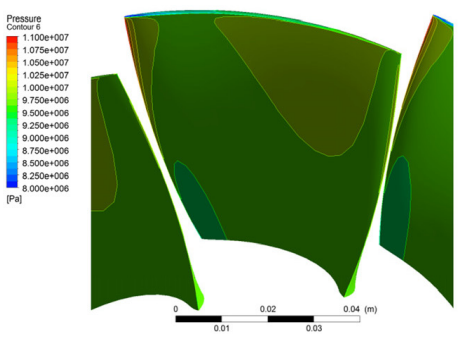

(a) $\delta=0.2 \mathrm{~mm}$

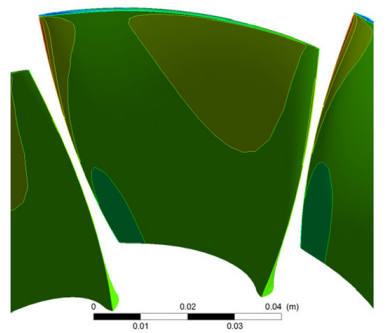

(b) $\delta=1 \mathrm{~mm}$

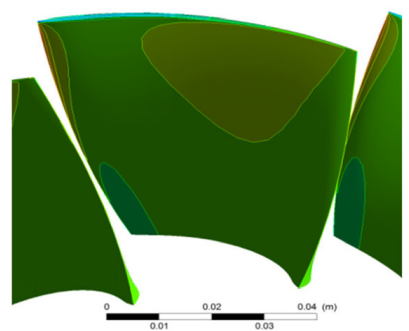

(c) $\delta=3 \mathrm{~mm}$

Fig. 17. The pressure contours of pressure side of rotor blade. 


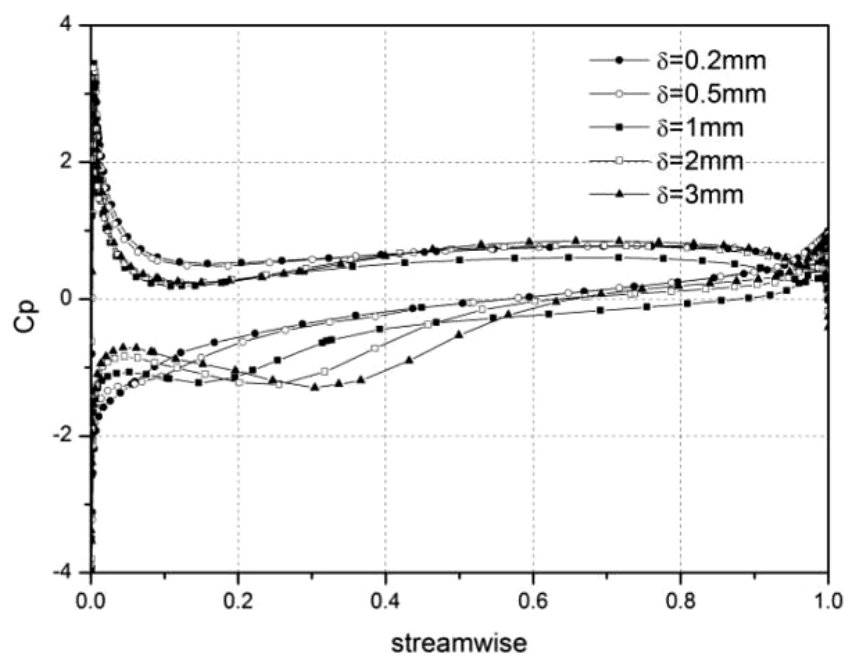

Fig. 18. The blade tip loading at constant span of 0.98 .

As is shown in Figs. 17 and 18 as the tip clearance increases, the low pressure area gradually moves from the leading edge to the trailing edge in the axial direction, and the affected area gradually increases. The lowest pressure coefficient $(C p)$ appears in the axial position at about $15 \%$ streamwise in the case $\delta=0.2 \mathrm{~mm}$, nevertheless, it appears at about $30 \%$ streamwise in the case $\delta=3 \mathrm{~mm}$. The low pressure zone affects the area from streamwise $10 \%$ to streamwise $20 \%$ of rotor blade at constant span of 0.98 in the case, however the area from streamwise $20 \%$ to streamwise $50 \%$ of rotor blade is affected in the case $\delta=3 \mathrm{~mm}$.

\subsection{Effects of different tip clearances on the velocity field of PJP}

Figure 19 shows the circumferential distribution of the axial velocity $\left(V_{x}\right)$, tangential velocity $\left(V_{i}\right)$ and radial velocity $\left(V_{r}\right)$ at different streamwises (streamwise = $0.1,0.9,1.9$ ) and radius ( $\operatorname{span}=0.2,0.5,0.8$ ) of PJP in the case $\delta=3 \mathrm{~mm}$ at $J=1.791$. Dimensionless treatment of velocity has been done according to the velocity of the inlet flow $(\mathrm{U}=25.72 \mathrm{~m} / \mathrm{s})$. A1, A2, A3 are at the inlet of rotor domain; B1, B2, B3 are at the middle section between the rotor and stator domain and $\mathrm{C} 1, \mathrm{C} 2, \mathrm{C} 3$ are at the outlet of stator domain.

(A1, A2, A3 are at the inlet of rotor domain; B1, B2, B3 are at the middle section between the rotor and stator domain; C1, C2, C3 are at the outlet of stator domain).

Figure19 (A1, A2 and A3) shows that the radial and tangential velocities at the inlet of rotor domain are small and the axial velocity is relatively large, conforming to the characteristics of the axial uniform free inlet flow. Due to the effect of the periodic rotation of rotor blade, the axial velocity exhibits a periodic oscillation and has 11 wave peaks and wave troughs. 
D. Qin et al.

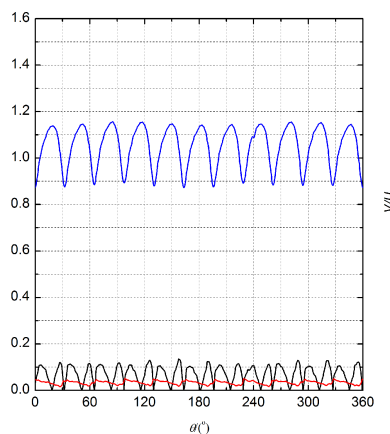

(A1) $\mathrm{span}=0.2$

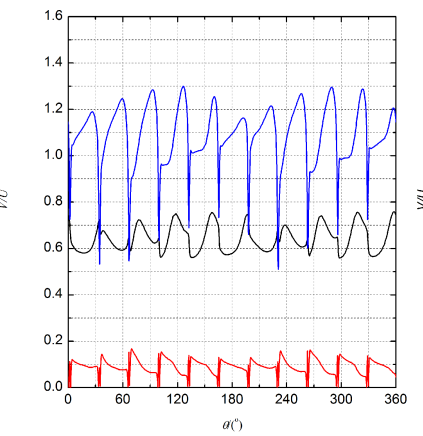

(B1) $\operatorname{span}=0.2(\mathrm{~B} 2)$

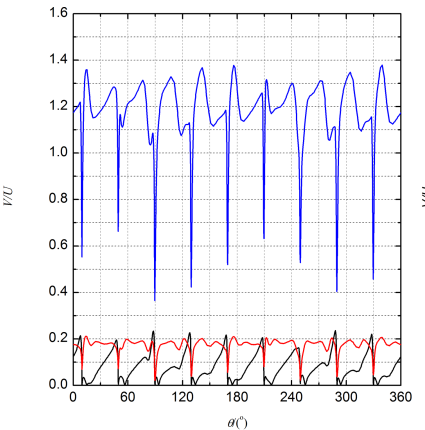

(C1) $\mathrm{span}=0.2$

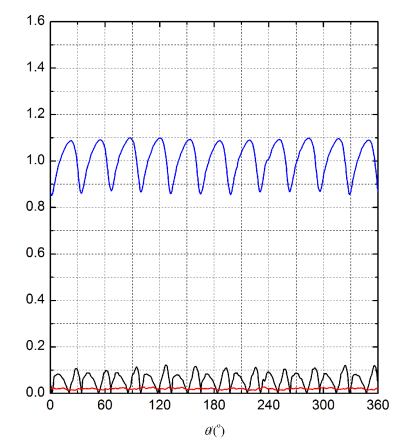

$-V / U-V_{r} / U-V_{r} / U$

(A2) $\quad$ span $=0.5$

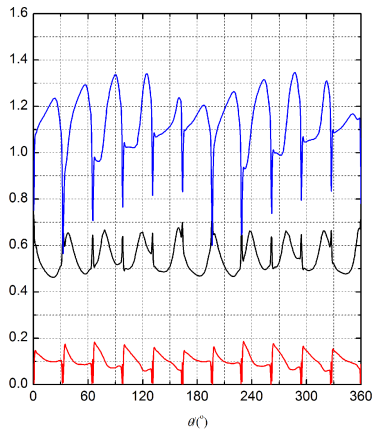

$-V / U-V_{r} / U-V_{x} U$

(B1) $\mathrm{span}=0.5$

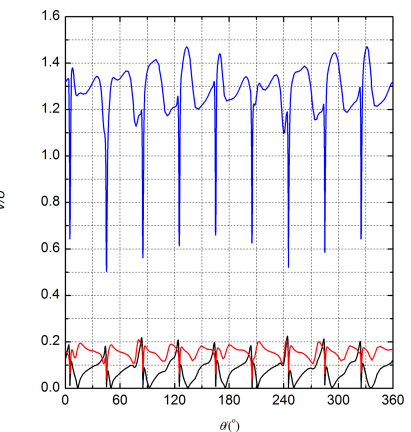

$-\mathrm{V} / \mathrm{U}-\mathrm{V}_{r} / \mathrm{U}-\mathrm{V}_{x} / \mathrm{U}$

(C2) $\operatorname{span}=0.5$

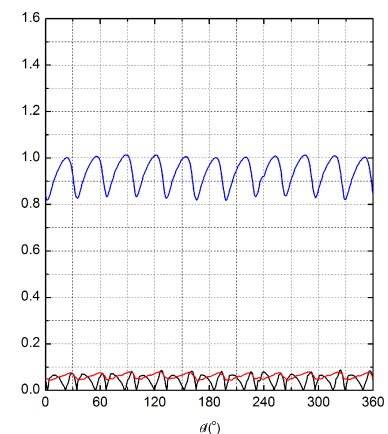

(A3) $\operatorname{span}=0.8$

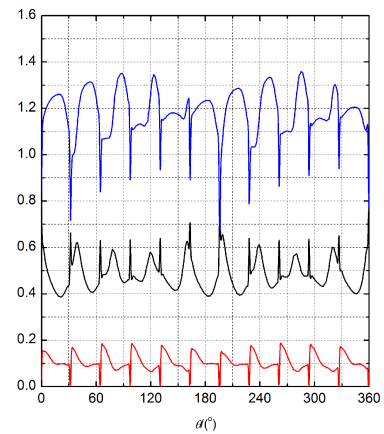

(B3) $\operatorname{span}=0.8$

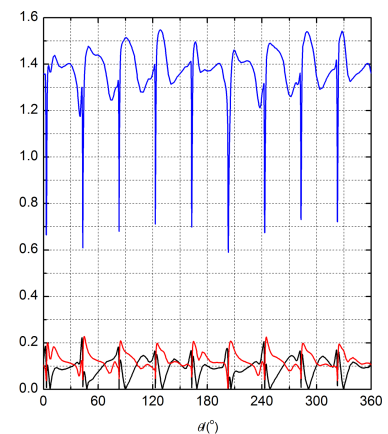

(C3) $\operatorname{span}=0.8$

Fig. 19. The circumferential distribution of the velocity components at different streamwises and radius of PJP in the case $\delta=3 \mathrm{~mm}$. 
From the numerical results of Fig. 19 (B1, B2 and B3), it can be seen that the axial and tangential velocities are bigger than the velocities at the inlet of rotor domain, whose peaks are about $1.3 \mathrm{U}$ and $0.7 \mathrm{U}$ compared with $1.1 \mathrm{U}$ and $0.1 \mathrm{U}$ $(\mathrm{U}=25.72 \mathrm{~m} / \mathrm{s})$ respectively at $\mathrm{span}=0.5$. The tangential velocity is becoming bigger because of the strong rotation of the rotor blade. Also, the axial velocity is becoming bigger due to that the fluid is accelerated by the rotation of the rotor blade. In addition, there are periodically very small velocity points of the axial velocity. It indicates that the axial velocity changes severely at the trailing edge of rotor blade due to the complex fluid, which may be affected by the tip-leakage vortex.

It can be seen from Fig. 19 (C1, C2 and $\mathrm{C} 3)$ that the axial velocity is becoming bigger, whose peaks is about $1.4 \mathrm{U}$ compared with $1.2 \mathrm{U}$ at B1, B2 and B3 at span $=0.5$, which is indicated that the flow is accelerated again by the stator blades . Furthermore, tangential velocity is significantly reduced from $0.6 \mathrm{U}$ to about $0.2 \mathrm{U}$ compared with the results of B1, B2, and B3. So the stator blades absorb the rotary energy very well, reducing the hydraulic loss of the thruster.

The axial velocity distribution at the outlet of PJP is very important for the design of thruster. Figures 20 and 21] show the axial velocity distributions of rotor blade at $\operatorname{span}=0.5$ and $\operatorname{span}=0.98$ respectively with different tip clearances.

Figure 20] shows that the difference of axial velocity distributions among the five tip clearances is small at span $=0.5$, and the velocity wave peaks and troughs are nearly equal. This is because that the main flow in the small radius area of the rotor passages is slightly affected by the vortex at the tip of the blade. However, it can be seen from Fig. 21 that the axial velocity distributions with different tip

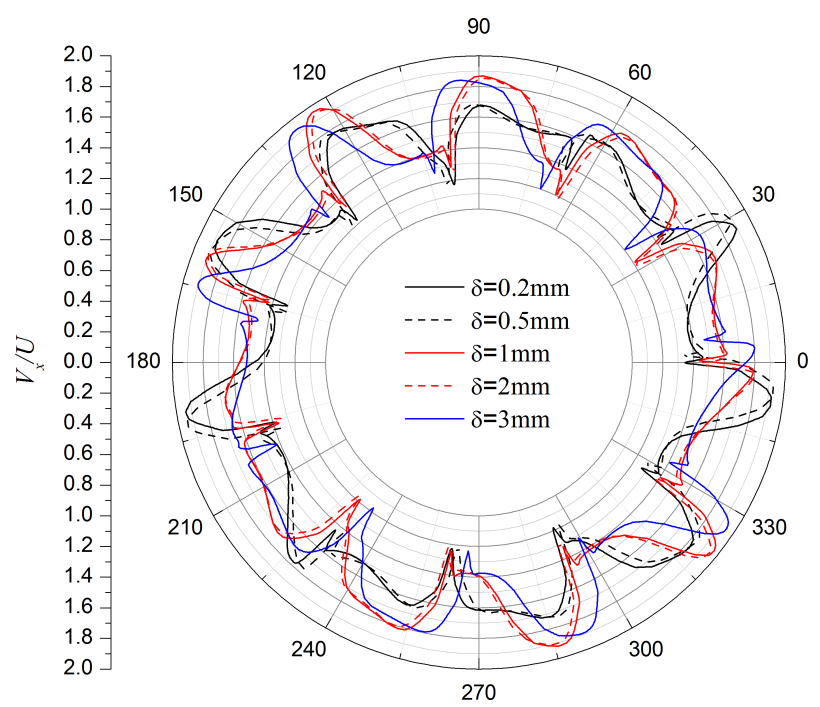

Fig. 20. The Axial velocity distributions of rotor blade at $\mathrm{span}=0.5$ with different tip clearances. 
D. Qin et al.

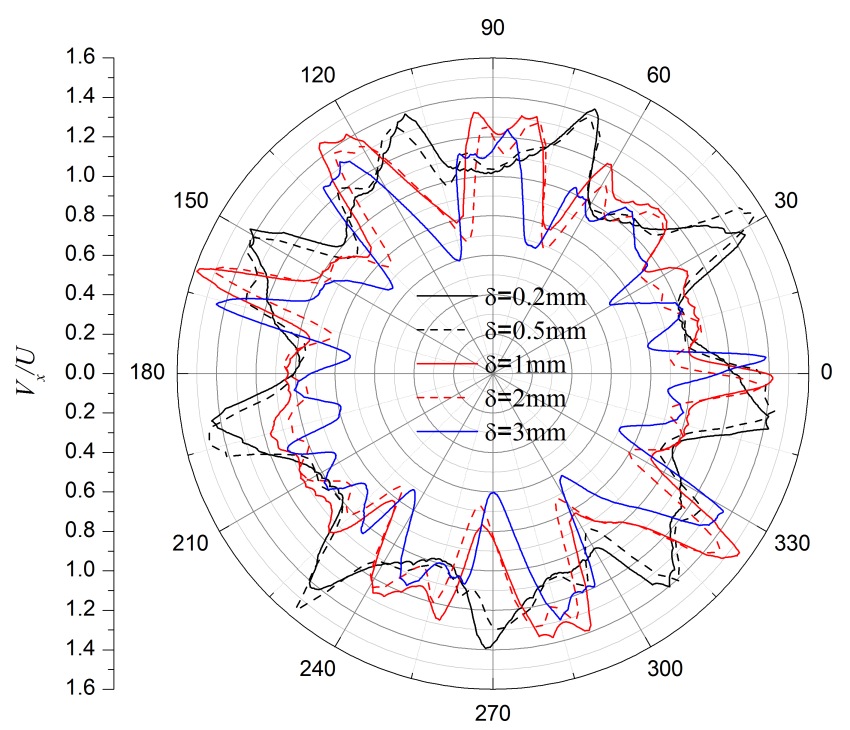

Fig. 21. The Axial velocity distributions of rotor blade at span $=0.98$ with different tip clearances.

clearances change greatly at span $=0.98$, which is in the area of rotor blade tip. Comparing the black solid line and black dotted line, the velocity curves coincide basically, which maybe because that the tip clearance leakage flow is still slight in the case $\delta=0.2,0.5 \mathrm{~mm}$. But from Fig. 15 it can be seen that as the tip clearance increases, the affected area of tip-leakage vortex is becoming larger and larger. So, there are obvious axial velocity wave troughs in the case $\delta=1,2,3 \mathrm{~mm}$ (about $0.6 \mathrm{U}$ ) compared with the value in the case $\delta=0.2,0.5 \mathrm{~mm}$ (about $1 \mathrm{U}$ ). The leakage intensity and range of the tip leakage vortex become larger and larger as the tip clearance increases, and there is more intense entrainment interference between the tip leakage flow and the main flow, which may results in the axial velocity reduction in the rotor passage and the propulsive efficiency reduction finally.

\section{Conclusions}

In this study, a pumpjet propulsor with different sizes of tip clearance $(\delta=0.2$, $0.5,1,2,3 \mathrm{~mm}$ ) has been presented to investigate the influence of the tip clearance on pumpjet propulsor. This analysis was carried out with RANS method, and the $S S T k-\omega$ turbulence model is applied. In order to verify the accuracy of numerical simulation method, calculations were carried out with a worldwide employed ducted propeller (the Ka4-70 propeller in 19A duct). It is indicated that the numerical simulation method with the $S S T k-\omega$ turbulence model with Automatic NearWall Treatment is applicable and reliable for PJP flows. And the grid independence validation is discussed. The numerical simulation of PJP flow with different tip clearances is carried out. The influences of the clearance on pumpjet propulsor are 
reflected in four aspects mainly.

(1) The open water efficiency decreases gradually with the increase of tip clearance. There is little relation between the variation of the open water efficiency and the increasing of the tip clearance after clearance greater than $2 \mathrm{~mm}$ (about $8 \% \mathrm{D})$.

(2) The tip vortex structure of PJP is mainly formed by two parts: the tipseparation vortex and the tip-leakage vortex. The rotor tip-separation vortex is caused by flow separation at the leading edge of the rotor blade tip, which spreads toward the suction surface and the affected area is becoming larger and larger as the tip clearance increases. And the rotor tip-leakage vortex caused by the pressure difference between pressure and suction side of the rotor blade is formed at the blade tip near the leading edge, which moves toward to midpassage with the spreading in the axial direction. Moreover, the affected flow area of tip-leakage vortex is becoming larger and larger too. Meanwhile, the tip-separation and tip-leakage vortexes are not independent but affect and contact mutually. The position contacted is moved to following edge in the axial direction with the increase of tip clearance.

(3) The main effected pressure area of different tip clearance mainly focus on the area above 0.9 spanwise of the rotor blade suction side, but the effect on the pressure of the rotor blade pressure side is not obvious. As the tip clearance increases, the low pressure area gradually moved from the leading edge to the following edge in the axial direction, and the effected region gradually increases.

(4) The rotor blade strongly rotates the flow field and increases the tangential and axial velocities of flow. And the stator blade absorbs the rotary energy very well and reduces the tangential velocity of flow. As the tip clearance increases, the axial velocity in the rotor domain shows an obvious decrease due to that the affected area of tip-leakage vortex is becoming larger and larger, which results in the propulsive efficiency reduction of PJP finally.

\section{Acknowledgment}

This work was supported by the National Natural Science Foundation of China (Grant No.51479170; No.51709229).

\section{References}

Bardina, J. E., Huang, P. G. and Coakley, T. J. [1997] "Turbulence modeling validation testing and development," NASA Technical Memorandum 110446 (see also Bardina, J. E., Huang, P. G. and Coakley, T. J., "Turbulence Modeling Validation", AIAA Paper 97-2121.)

Booth, T. [1985] Importance of tip clearance flows in turbine design, VKI lecture series, 1985-05: Tip clearance effects in axial turbomachines (Von Karman Institute for Fluid Dynamics, Belgium).

Documentation, A. N. S. Y. S. [2002] Ansys Inc. Canonsburg, PA. 
Ivanell, S. [2001] "Hydrodynamic simulation of a torpedo with pump jet propulsion system," Master thesis, Royal Institute of Technology, Stockholm.

Jeong, J. and Hussain, F. [1995] "On the identification of a vortex," J. Fluid Mech. 285, 69-94.

Ji, B., Luo, X., Wu, Y., Liu, S., Xu, H. and Oshima, A. [2010] "Numerical investigation of unsteady cavitating turbulent flow around a full scale marine propeller," Proc. 9th Int. Conf. on Hydrodynamics, October 11-15, Shanghai, China.

Lee, Y. T., Hah, C. and Loellbach, J. [2003] "Flow analyses in a single-stage propulsion pump," J. Turbomach. 118(2), 240-248.

Lu, L., Pan, G., Wei, J. and Pan, Y. [2016] "Numerical simulation of tip clearance impact on a pumpjet propulsor," Int. J. Naval Archit. Ocean Eng. 8, 219-227.

Mccarter, A. A., Xiao, X. and Lakshminarayana, B. [2001] "Tip clearance effects in a turbine rotor: Part II-velocity field and flow physics," J. Turbomach. 123(2), 305-313.

Menter, F. R. [1994] "Two-equation eddy-viscosity turbulence models for engineering applications," AIAA-J. 32(8), 1598-1605.

Morgut, M. and Nobile, E. [2012] "Influence of grid type and turbulence model on the numerical prediction of the flow around marine propellers working in uniform inflow," Ocean Eng. 42, 26-34.

Oosterveld, M. W. C. [1970] Wake Adapted Ducted Propellers (Delft University of Technology, TU Delft).

Pan, G., Hu, B., Wang, P., Yang, Z. and Wang, Y. [2013] "Numerical simulation of steady hydrodynamic performance of a pump-jet propulsor," J. Shanghai Jiao Tong Univ. 47, 932-937.

Peng, H., Qiu, W. and Ni, S. [2013] "Effect of turbulence models on RANS computation of propeller vortex flow," Ocean. Eng. 72(1), 304-317.

Suryanarayana, Ch. et al. [2010] "Experimental evaluation of pumpjet propulsor for an axisymmetric body in wind tunnel," Int. J. Naval Archit. Ocean Eng. 2, 24-33.

Xiao, X., Mccarter, A. A. and Lakshminarayana, B. [2001]. "Tip clearance effects in a turbine rotor: Part I-pressure field and loss," Trans. ASME-T-J. Turbomach. 123(2), 296-304.

Yaras, M. and Sjolander, S. [1992] "Effects of simulated rotation on tip leakage in a planar cascade of turbine blades: Part Itip gap flow," J. Turbomach. 114(3), 652-659.

Yaras, M., Sjolander, S. and Kind, R. [1992] "Effects of simulated rotation on tip leakage in a planar cascade of turbine blades: Part II-downstream flow field and blade loading," J. Turbomach. 114(3), 660-667.

You, D., Wang, M., Moin, P. and Mittal, R. [2007] "Large-eddy simulation analysis of mechanisms for viscous losses in a turbomachinery tip-clearance flow," J. Fluid Mech. 586, 177-204. 